\title{
STUDIES OF THIAMINE METABOLISM IN MAN. II. THIAMINE AND PYRIMIDINE EXCRETION WITH SPECIAL REFERENCE TO THE RELATIONSHIP BETWEEN INJECTED AND EX- CRETED THIAMINE IN NORMAL AND ABNORMAL SUBJECTS ${ }^{1}$
}

\author{
By BENJAMIN ALEXANDER, GRETA LANDWEHR, AND FRANCES MITCHELL \\ (From the Medical Service and Medical Research Laboratories, Beth Israel Hospital, and the \\ Department of Medicine, Harvard Medical School, Boston)
}

(Received for publication August 6,1945)

Although numerous attempts have been made to devise tests for thiamine nutrition based upon the urinary excretion of the vitamin after its oral or parenteral administration ( 1 to 9 ), the relationship between the dose of the vitamin given and the amount which can be recovered in the urine is obscure. Thiamine administered orally or parenterally rapidly appears in the urine, but the increment in the urine after a single dose represents only a fraction of the total amount given $(10,11$, 6) and the fate of the remainder is unknown.

The difference between the amount of thiamine administered and the amount excreted may be explained in part by storage of the vitamin in the body. Tissue $B_{1}$ in dogs can be increased by daily injections of the vitamin (12), but the increase is too small to account for the large losses of administered thiamine. In man, studies of tissue thiamine concentration before and after $B_{1}$ administration are not feasible; a few observations on autopsy material from subjects who received thiamine parenterally indicate some storage of the vitamin (13), but not enough to account for the amount of administered thiamine which fails to appear in the urine. Furthermore, administration of $B_{1}$ supplements over a prolonged period should saturate the tissues. Yet even under such conditions (14, 15) urinary thiamine accounts for only a fraction of the total $B_{1}$ administered.

Urine normally contains both thiamine and another substance which accelerates yeast fermentation (16). The urinary concentration of this substance, as well as of thiamine, increases after the oral or parenteral administration of thiamine supplements $(14,15,17)$. Little is known regarding the factors which influence the conversion of the

\footnotetext{
1 This investigation was aided by a grant from the Josiah Macy, Jr. Foundation.
}

vitamin to this substance, and the excretion of the latter in relation to thiamine intake also requires elucidation.

This investigation was designed to clarify the following points :

1. The relation between the intake and excretion of thiamine in normal and abnormal subjects.

2. The fate of that portion of administered thiamine which cannot be recovered in the urine.

3. The relation between the intake of thiamine and the excretion of the non-thiamine factor which accelerates yeast fermentation. Throughout this paper this substance is referred to as "pyrimidine" or as "PAYF."

4. The rate of excretion of excessive stores of thiamine.

\section{METHOD}

Experiments were done on 10 subjects, of whom 6 were normal, 1 had hyperthyroidism and 3 were chronic diabetics. One of the latter also had carcinoma of the pancreas. In all the experiments thiamine was administered intramuscularly. In 3 of the normal individuals and in all the abnormal subjects thiamine was given daily for from 2 to 5 days in doses which ranged from 8.8 to $100 \mathrm{mgm}$. In some individuals the experiment was repeated with the same or a different dose. In the other 3 normal subjects the daily dose was increased every day or every 3 days over periods of from 9 to 37 days. In the first (B. A.) the dose which was initially $1.0 \mathrm{mgm}$. was approximately doubled ${ }^{2}$ every third day until it reached $144 \mathrm{mgm}$; it was then reduced gradually until it reached zero. Urinary thiamine was followed for 2 weeks after injections of the vitamin were discontinued. Two months later, in a similar experiment, the dose was increased daily over a period of 19 days from 0.5 to $35 \mathrm{mgm}$. The procedure of doubling the daily dose of thiamine every third day was followed in the second normal subject (G. L.) for 15 days; thereafter the dose was varied by increments of 5 to $30 \mathrm{mgm}$. every third day for 12 days.

\footnotetext{
2 Strict geometric progression could not be followed because of slight variations in concentration of the prepared thiamine solutions.
} 


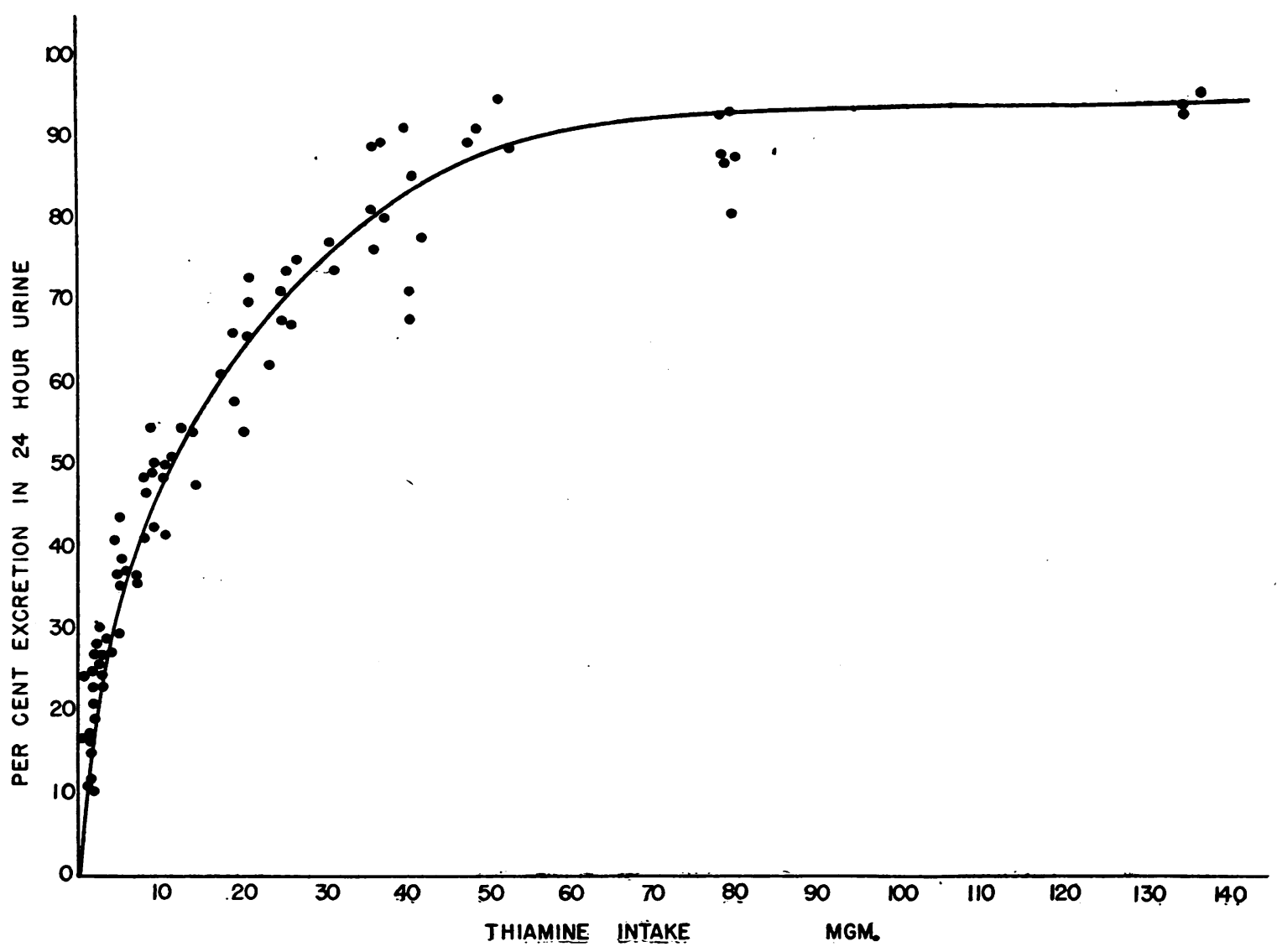

Fig. 1. Thiamine Excretion (in Percentage of the Daily Dose) in the 24-Hour Urine of Three Normal Subjects (B. A., G. L., F. M.)

Urinary thiamine excretion was followed for 12 more days after supplementary thiamine was discontinued. Several months later thiamine excretion was studied following single injections of the vitamin in different doses. In the third normal subject (F.M.) 2 experiments were done in which the dose was varied by daily increments of approximately 5 and $12 \mathrm{mgm}$. respectively. The first experiment lasted 11 days and was followed by an 8-day period of observation during which no supplements of thiamine were given. The second experiment, done several months later, lasted 7 days.

The daily oral intake of thiamine for all subjects was calculated from standard tables. ${ }^{8}$ Thiamine injections were given at approximately the same time each day, and the total urine excreted during each subsequent 24 hours was collected and analyzed for thiamine by a specific chemical method (18).

In 3 of the normal subjects (B. A., G. L., F. M.) urinary pyrimidine was also determined for at least one experimental period. The pyrimidine was calculated by estimating the total thiamine and pyrimidine from the total

${ }^{3}$ Applied Dietetics. Frances Stern. Williams and Wilkins Co., Baltimore, 1943. yeast fermentation accelerating power of the urine in the Warburg apparatus (16) and then subtracting the values for thiamine obtained by chemical analysis. A figure for the pyrimidine accelerating yeast fermentation (PAYF) was thus obtained.

\section{RESULTS}

Relation between the intake of thiamine and its excretion in the urine of normal subjects. Subject 1 (H. L.) received $94 \mathrm{mgm}$. of thiamine intramuscularly and $1.0 \mathrm{mgm}$. orally (in the diet) each day for 5 days. Seventy-five per cent of the total intake of the vitamin was recovered as such in the urine excreted during this 5-day interval.

Subject 2 (S. W.), who received in one day a total of $9.8 \mathrm{mgm}$. of the vitamin $(8.8 \mathrm{mgm}$. intramuscularly and $1.0 \mathrm{mgm}$. in the diet), excreted 31 per cent of the total intake in the urine. Five days later, on the same intake each day for 2 days, he excreted 56 per cent.

Subject 3 (W. S.) received $14 \mathrm{mgm}$. of $B_{1}$ 


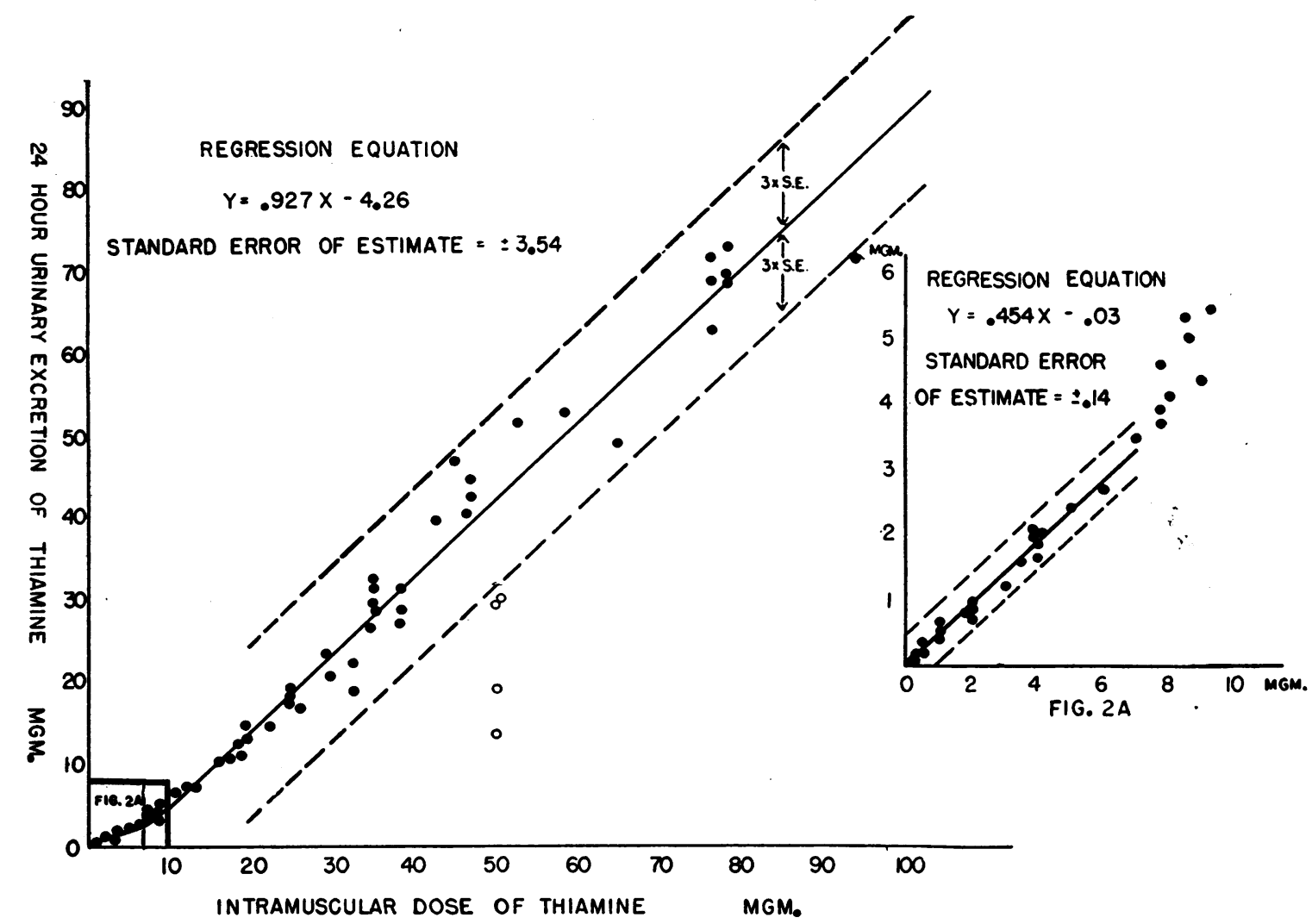

Fig. 2, 2A. Relation Between Amount of Thiamine Injected Parenterally and Its Excretion in the Subsequent 24 Hours

Solid dots represent observations on normal subjects; observations on abnormal subjects are indicated by open circles

(13.2 mgm. parenterally) daily for 2 days; approximately 43 per cent was excreted in the urine.

The variations in the fractions of the administered thiamine which was excreted by these subjects indicated the need for further detailed study of the dose-excretion relationship; this was carried out on the other 3 normal subjects (B. A., G. L., F. M.). All gave a uniform pattern of urinary thiamine excretion in relation to the intake of the vitamin (Figure 1). As the dose was increased, the percentage of it excreted rose; with intakes of more than $50 \mathrm{mgm}$. the excretion approached, but never reached, 100 per cent.

A plot of the urinary thiamine excretions against the doses of parenteral thiamine for all the normal subjects gave a curve. which could be broken down into two linear segments (Figures 2, 2A). One segment, covering doses of zero to $7 \mathrm{mgm}$., was represented by the equation $Y=0.454 X-0.03$, where $Y$ and $X$ equal the excretion and the intra- muscular injection, in mgm., respectively. For the other segment, which covered doses of more than $10 \mathrm{mgm}$., the equation was $Y=0.927 X$ -4.26 .

Thiamine excretion in abnormal subjects. The thiamine excretions of the 4 abnormal subjects were lower than those obtained on normal individuals by amounts that were outside of 3 times the standard error of estimate (Table I, Figure 2). One of the subjects with diabetes (SchneiderTable I) excreted a small amount of thiamine (4 mgm.) in the 48-hour period following discontinuation of parenteral thiamine supplements. This amount is comparable with the $B_{1}$ excretions of normal subjects described below (Figure 3 ).

Pyrimidine excretion. Those normal subjects in whom the urinary pyrimidine (PAYF) was determined excreted between 0.5 and $0.7 \mathrm{mgm}$. of this material daily when the diet was the only source of thiamine. As the intake of the vitamin 
TABLE I

Thiamine excretion in disease

\begin{tabular}{|c|c|c|c|c|c|c|}
\hline \multirow{2}{*}{ Subject } & \multirow{2}{*}{ Sex } & \multirow{2}{*}{ Diagnosis } & \multirow{2}{*}{$\begin{array}{c}\text { Period } \\
\text { of } \\
\text { study }\end{array} \mid$} & \multirow{2}{*}{$\begin{array}{c}\text { Daily } \\
\text { thi- } \\
\text { amine } \\
\text { dose }\end{array}$} & \multicolumn{2}{|c|}{$\begin{array}{c}\text { Urinary } \\
\text { excretion }\end{array}$} \\
\hline & & & & & Found & $\underset{\text { pected* }}{\text { Ex- }}$ \\
\hline Adelman & q & Diabetes & $\begin{array}{c}\text { days } \\
7\end{array}$ & $\begin{array}{r}m g m . \\
50\end{array}$ & $\mid$\begin{tabular}{|} 
mgm. \\
19.5
\end{tabular} & $\begin{array}{l}\text { per } 24 \text { hrs. } \\
\mid 31 \text { to } 51\end{array}$ \\
\hline Adelman & 9 & Diabetes & 5 & 50 & 12.7 & 31 to 51 \\
\hline $\begin{array}{l}\text { Levinson } \\
\text { Schneider } \\
\text { Caplan, G. }\end{array}$ & $\begin{array}{l}07 \\
07 \\
8\end{array}$ & $\begin{array}{l}\text { Diabetes } \\
\text { Diabetes } \\
\text { Hyper- } \\
\text { thyroidism }\end{array}$ & $\begin{array}{l}6 \\
7 \\
3\end{array}$ & $\begin{array}{r}50 \\
100 \\
50\end{array}$ & $\begin{array}{l}29.5 \\
62.0 \\
30.2\end{array}$ & $\begin{array}{l}31 \text { to } 51 \\
78 \text { to } 99 \\
31 \text { to } 51\end{array}$ \\
\hline
\end{tabular}

* On the basis of excretion curves (Figs. 2, 2A) of normal subjects on same dose. Range covers plus or minus three times standard error of estimate.

was increased by parenteral administration, urinary PAYF also increased (Table II). In the 3 subjects (B. A., G. L., F. M.) urinary $B_{1}$ plus py- rimidine accounted for practically all of the thiamine taken (Table III).

Thiamine excretion in normal subjects following discontinuation of large parenteral doses. The injection of thiamine was followed by the excretion in the urine of a large fraction of the dose during the subsequent 24 hours. A much smaller fraction can be recovered during the second 24-hour period and still smaller amounts in the days following (Figure 3). In those experiments where thiamine was given daily for many days, some of the vitamin which was excreted in any 24-hour urine may have been due to $B_{1}$ overflow from preceding days' injections. When, however, corrections are applied for the amounts which may thus be involved, the excretion curve is not altered significantly. Furthermore, the per cent excretions of single doses were almost as high as when the same dose was administered as part of a series of daily injections. The excretion curves in Figures 2 and

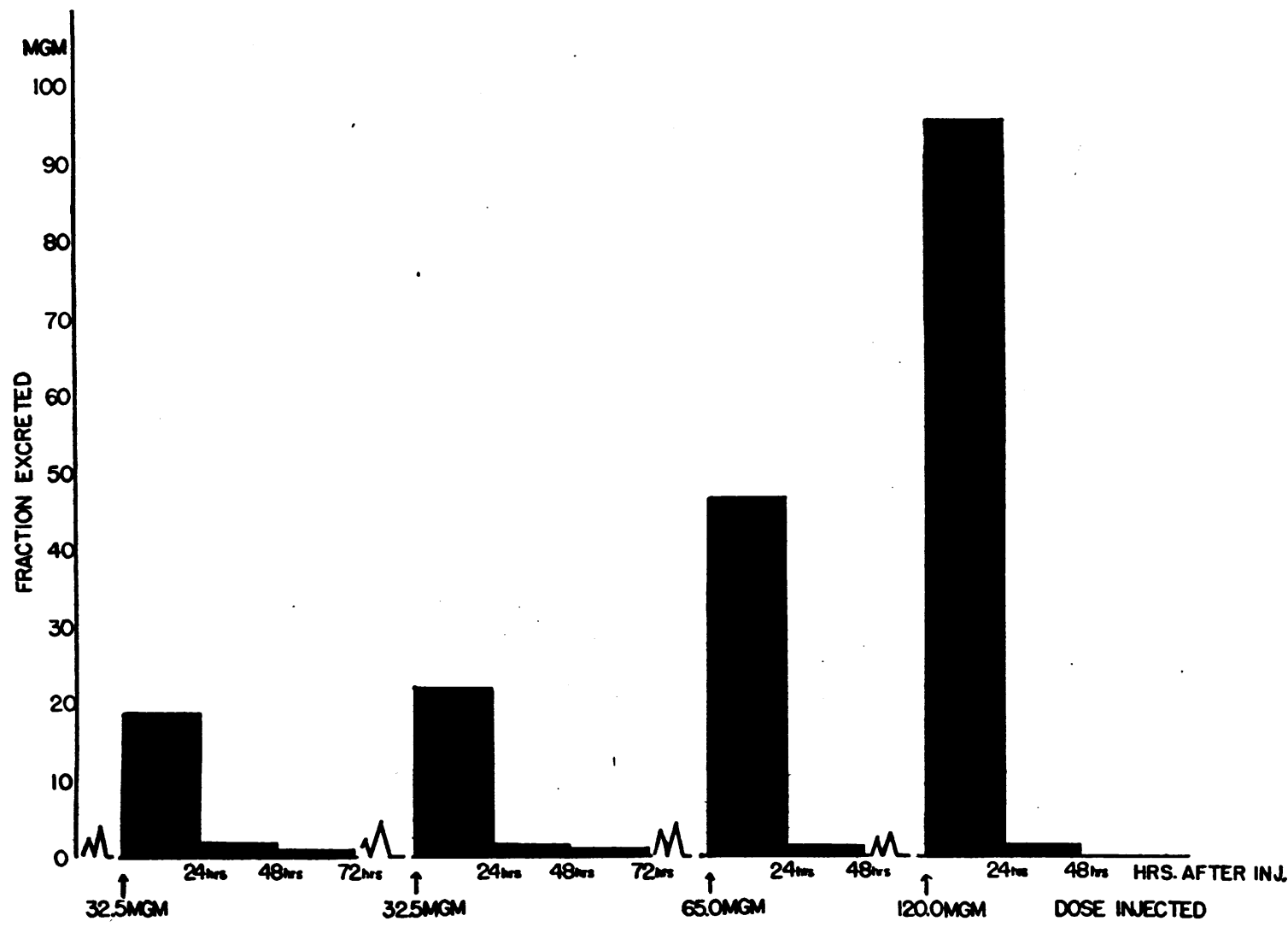

Fig. 3. The Excretion of Thiamine Per 24 Hours After the Injection of Single Doses of the Vitamin in Normal Subjects 
TABLE II

Pyrimidine excretion (PAYF) in relation to thiamine intake in normal subjects

\begin{tabular}{|c|c|c|c|c|}
\hline \multirow{2}{*}{ Subject } & \multicolumn{2}{|c|}{ Thiamine intake } & \multirow{2}{*}{ Total } & \multirow{2}{*}{$\underset{\text { excretion }}{\text { PAYF }}$} \\
\hline & Oral & Parenteral & & \\
\hline B. A. & $\begin{array}{c}m g m . \\
1.50 \\
1.25 \\
1.00 \\
1.44 \\
1.04 \\
1.15 \\
1.86 \\
1.36\end{array}$ & $\begin{array}{c}m g m . \\
0 \\
1.00 \\
2.00 \\
3.80 \\
8.00 \\
17.30 \\
38.40 \\
76.60\end{array}$ & $\begin{array}{r}\text { mgm. } \\
1.50 \\
2.25 \\
3.00 \\
5.24 \\
9.04 \\
18.50 \\
40.30 \\
78.00\end{array}$ & $\begin{array}{r}\text { mgm.* } \\
0.60 \\
0.70 \\
1.32 \\
3.13 \\
3.44 \\
6.08 \\
6.04 \\
10.90\end{array}$ \\
\hline G. L. & $\begin{array}{l}1.09 \\
1.21 \\
1.06 \\
0.80 \\
0.84 \\
0.67 \\
0.78 \\
0.97 \\
0.88 \\
1.60 \\
0.80\end{array}$ & $\begin{array}{r}0 \\
1.00 \\
2.00 \\
3.88 \\
7.75 \\
12.30 \\
19.70 \\
24.60 \\
35.20 \\
47.00 \\
78.50\end{array}$ & $\begin{array}{r}1.09 \\
2.21 \\
3.06 \\
4.68 \\
8.59 \\
13.00 \\
20.50 \\
25.60 \\
36.10 \\
48.60 \\
79.30\end{array}$ & $\begin{array}{l}0.50 \\
0.72 \\
1.17 \\
0.86 \\
1.63 \\
2.38 \\
4.12 \\
6.83 \\
8.75 \\
8.80 \\
9.40\end{array}$ \\
\hline F. M. & $\begin{array}{l}1.69 \\
0.85 \\
1.30 \\
1.30 \\
1.24 \\
2.30 \\
1.40 \\
2.50 \\
1.10 \\
0.90 \\
2.10 \\
1.40\end{array}$ & $\begin{array}{c}0 \\
4.50 \\
9.00 \\
13.60 \\
18.10 \\
22.60 \\
29.20 \\
35.00 \\
42.80 \\
46.60 \\
52.40 \\
58.30\end{array}$ & $\begin{array}{r}1.69 \\
5.35 \\
10.30 \\
14.90 \\
19.30 \\
24.90 \\
30.60 \\
37.50 \\
43.90 \\
47.50 \\
54.50 \\
59.70\end{array}$ & $\begin{array}{r}0.64 \\
1.00 \\
2.10 \\
2.50 \\
7.30 \\
5.30 \\
12.40 \\
15.60 \\
6.00 \\
14.10 \\
13.30 \\
24.00\end{array}$ \\
\hline & $\begin{array}{l}1.50 \\
1.50 \\
1.50 \\
1.50 \\
1.50 \\
1.50\end{array}$ & $\begin{array}{r}6.25 \\
12.50 \\
25.00 \\
37.50 \\
50.00 \\
62.50\end{array}$ & $\begin{array}{r}7.75 \\
14.00 \\
26.50 \\
39.00 \\
51.50 \\
64.00\end{array}$ & $\begin{array}{r}3.08 \\
3.00 \\
8.00 \\
14.10 \\
24.60 \\
20.8\end{array}$ \\
\hline
\end{tabular}

* In terms of thiamine.

TABLE III

Thiamine balance in normal subjects

\begin{tabular}{|c|c|c|c|}
\hline Subject & B.A. & G.L. & F.M. \\
\hline $\begin{array}{l}\text { Sex } \\
\text { Interval of study (days) } \dagger \\
\text { Total thiamine intake (grams) } \\
\text { Total thiamine excreted (grams) } \\
\text { Total PAYF excreted (grams)* } \\
\text { Total } \text { B }_{1} \text { plus PAYF excreted } \\
\text { (grams)* } \\
\text { Thiamine unaccounted for (grams) }\end{array}$ & \begin{tabular}{c|}
$\sigma^{7}$ \\
51 \\
1.086 \\
0.887 \\
0.183 \\
1.060 \\
0.026
\end{tabular} & $\begin{array}{c}9 \\
42 \\
0.621 \\
0.502 \\
0.118 \\
\\
0.620 \\
0.001\end{array}$ & $\begin{array}{c}9 \\
21 \\
0.365 \\
0.291 \\
0.123 \\
0.414\end{array}$ \\
\hline
\end{tabular}

† Interval of study includes 2 to 3 days before, and 8 to 15 days after, series of thiamine injections.

* Expressed in terms of thiamine.
2A include the observations for excretions following single injections.

Further study of urinary thiamine excretion in normal subjects following termination of the series of thiamine injections, revealed that in 3 subjects (B. A., G. L., F. M.) the rate of decrease in the amount of the vitamin excreted was uniform (Figure 4). When the logarithm of the urinary $B_{i}$ was plotted against the logarithm of the day of observation, a linear relationship was obtained:

$$
10 \log x=1.5474-1.1810 \log y
$$

where $x$ and $y$ represent the thiamine excretion in $\mathrm{mgm}$. and the day of observation respectively. Day 1 was the second 24-hour period following the last injection, day 2 the third 24-hour period, etc. This relationship did not apply to the daily thiamine excretion following single doses of the same size.

\section{DISCUSSION}

The excretion of thiamine into the urine by normal subjects is directly related to the amount of the vitamin administered. The relationship can be expressed by linear equations representing two curves of different slopes. The first curve, with a slope of 0.45 , obtains for doses of less than $7 \mathrm{mgm}$. The slope rises rapidly between doses of 7 and 10 mgm., above which the curve again becomes linear, with a slope of 0.93 . This relationship seems to hold, regardless of how the dose is varied.

That the urinary excretions following isolated injections of thiamine fall within the excretion range established by observations based on a series of daily injections indicates that the metabolism of the vitamin is independent of thiamine given on previous days. This is also in accord with the observation that most of the urinary thiamine arising from any injection of the vitamin is excreted within the first 24 hours.

Although the reported values for thiamine excretion in response to injections of the vitamin (19 to $21,1,4,8,10,11$ ) are generally somewhat lower (Table IV) than the theoretical values computed from the dose by means of the equations for excretion described above, the pattern of increasing per cent excretion with increasing dose is in accord. Since the data of most other observers are based upon the results of single injections of the 


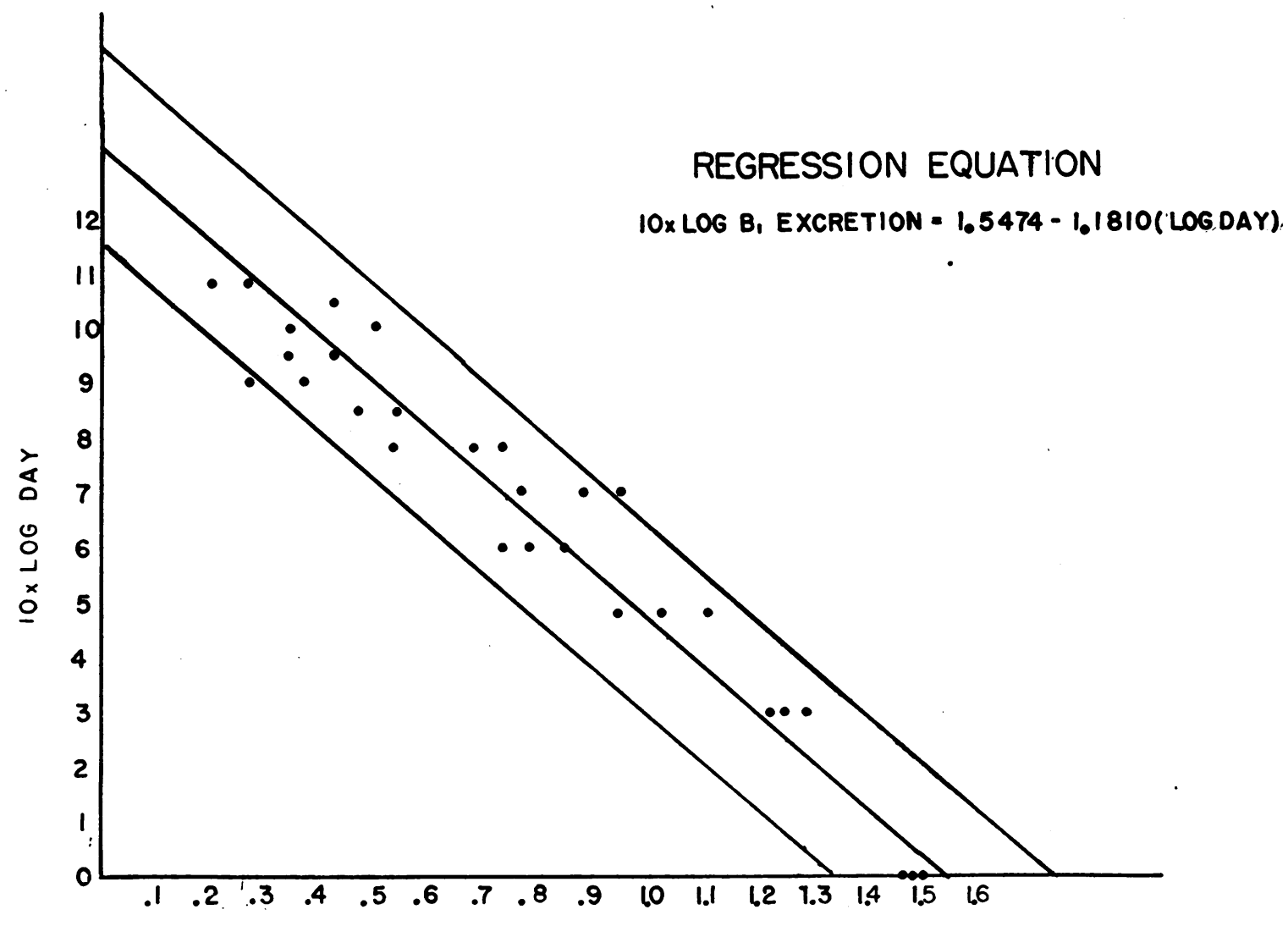

IOXLOG B, EXCRETION

Fig. 4. Daily Urinary Thiamine Excretion After Thiamine Saturation in Normal Subjects $B_{1}$ excretion is in mgm.; day 1 is second 24 -hour period after last injection, day 2 is third 24-hour period, etc.

vitamin, it is probable that the tissues of their subpects were not saturated and accordingly stored some of the administered vitamin.

A few investigators reported patterns of thiamine excretion which were at variance with our results. Lockhart et al. (22), who administered the vitamin parenterally to normal and pregnant women in increasing amounts, found a peak of excretion of about 10 per cent at doses of approximately $3 \mathrm{mgm}$. As the dose was increased above this amount, the percentage of it which was excreted fell rapidly until only 2 per cent could be recovered when the dose was 10 or more mgm. Drigalski (20) found that the injection of 10 mgm. of the vitamin daily for 8 days resulted on the first 2 days in a daily urinary thiamine excretion of about $5 \mathrm{mgm}$., which gradually decreased to $0.2 \mathrm{mgm}$. by the eighth day.
The equations describing the urinary thiamine excretion in normal subjects are applicable to studies of pathological conditions where thiamine metabolism and excretion may be deranged, as, for example, diabetes mellitus and hyperthyroidism. It has been claimed that thiamine metabolism is disturbed in these diseases (23 to 25 ). In support of these claims are the abnormal excretions of the vitamin observed in these subjects (Table I). In both conditions the thiamine excretions in relation to doses administered were lower than those obtained for the same doses in normal subjects. While more observations are needed to elucidate the nature and extent of the disturbance in $B_{1}$ metabolism, the data indicate that a greater fraction of administered thiamine is destroyed in these diseases than in normal individuals. As will be shown later, simultaneous determinations 
TABLE IV

Thiamine excretion in response to injection as reported in the literature



* Excreted within 24 hours after injection except as otherwise indicated.

† As computed by excretion equations obtained on normal subjects (Figs. 2, 2A). Range covers plus or minus three times standard error of estimate.

¥ Within 8 hours after injection.

Authors admit possibility of this value being 30 per cent too low.

of urinary pyrimidine would have been of great value in establishing the fate of that portion of the administered vitamin which was not excreted as such.

For similar studies in various pathological conditions, selection of the dose range will be determined by the particular purpose of the study. In investigations of the requirements or storage of thiamine or the nutritional status of individuals with regard to the vitamin, the lower dose range would be preferable, since differences in thiamine excretion might be expected to be of the order of a few mgm. which might be obscured by the large excretions consequent to the administration of large doses. Studies of thiamine conversion to pyrimidine, on the other hand, may be more advantageously approached by employing the higher dose range.

The capacity of the body for storage of thiamine is limited to two or three times the amount normally present. By daily administration of large amounts of the vitamin complete saturation of body stores is assured. Under such circumstances the difference between injected thiamine and thiamine excreted in the urine cannot be ascribed to storage of the vitamin in the tissues. Neither can it be explained by excretion into, and loss via, the gastrointestinal tract $(26,10,12)$. The rapid rise in urinary pyrimidine consequent to thiamine administration indicates a ready conversion of the vitamin to this substance. While the significance of this reaction is obscure, it explains most of the differences between injected and excreted thiamine, since the sum of the PAYF and $B_{1}$ in the urine is almost equal to the thiamine intake. Although small amounts of thiamine (about $1 \mathrm{mgm}$. daily) are consumed normally in other ways (17), the degradation of administered thiamine consists essentially of its conversion to pyrimidine. This reaction probably explains the difference in slope of the two segments of the thiamine excretion curve. At thiamine doses of less than $7 \mathrm{mgm}$., the amount of thiamine converted to pyrimidine is proportional to the dose of the vitamin administered. At doses of more than $10 \mathrm{mgm}$., the maximal amount of thiamine which the body can convert to pyrimidine has been reached and the rest of the thiamine is excreted as such. In this range the theoretical slope of the thiamine excretion curve would be unity. The found slope was 0.93 .

Further evidence in support of this interpretation is provided by a plot of the dose of thiamine against the excretion of thiamine plus pyrimidine (Figure 5) in 2 normal subjects (B. A., G. L.). The relationship is linear throughout with a slope of 1 ; this indicates that the bend in the original excretion curve (Figures 2, 2A) is due to the fact that maximal $B_{1}$ conversion to pyrimidine is reached at that point. Practically all of the thiamine can be recovered as the vitamin or as its pyrimidine breakdown product.

Although some of the injected thiamine will appear in the urine for several days after any single injection, most of it is excreted within the first 24 hours (Figure 3). Other investigators $(10,19,20)$ claim that the urine excreted within 3 hours after injection of the vitamin contains most of the $B_{1}$ overflow. Following injection, furthermore, the rises in blood thiamine are remarkably transient (27). Borsook (28), employing thiamine tagged with radioactive sulfur, found that the transport of the injected vitamin to the tissues and its interchange with the thiamine al- 




Fig. 5. Relation Between the Intake of Thiamine and the Excretion of the Vitamin Plus Its Pyrimidine Breakdown Product (Expressed in terms of thiamine)

Each value represents the average excretion for three consecutive days on the same intake.

Broken line represents excretion curves of Figs. 2, 2A.

ready there is rapid. Accordingly, the sequence of events following the parenteral administration of thiamine may be regarded as follows: the injected vitamin enters the blood stream and is rapidly transported to the tissues, where it is converted, at least in part, to cocarboxylase. Some of the thiamine is converted to pyrimidine. This, together with whatever thiamine cannot be retained by the tissues, is retransported to the kidneys and is excreted in the urine.

Thiamine overflow into the urine continues at a certain rate for many days after injection of the vitamin is discontinued. In 3 normal subjects who received daily injections of thiamine in increasing amounts for many days $(34,58,78 \mathrm{mgm}$. respectively were the largest doses), the daily urinary excretion of $B_{1}$ following discontinuation of thiamine supplements was related to the day of observation; between certain limits it was independent of the size of the daily dose and of the total dose administered. It would seem that this relationship, which was linear when the logarithm of the day was plotted against the logarithm of the excretion (Figure 4), describes the speed of mobilization and excretion of excess amounts of tissue thiamine after the initial flooding effects of large doses of the vitamin have been obviated. More significant, perhaps, is the fact that increasing the daily doses to more than $34 \mathrm{mgm}$. did not result in higher excretion values in the days following the last injection; this would indicate that such doses did not result in storage of larger 
amounts of thiamine. It is possible that doses of less than $34 \mathrm{mgm}$. daily would also result in maximal storage of thiamine. Although the daily urinary thiamines following a single injection of the vitamin in amounts of between 34 and 78 mgm. were always lower than those represented in Figure 4, it is probable that the same slope would be maintained, but at a lower level. The relationship describing thiamine excretion following discontinuation of injection of supplements of the vitamin may also be used in studies of $B_{1}$ metabolism and excretion in abnormal subjects.

Since the major portion of thiamine administered in daily doses of more than $10 \mathrm{mgm}$. is rapidly excreted in the urine, and since doses of more than $34 \mathrm{mgm}$. do not result in greater storage of thiamine in the tissues, there seems no justification for the use of larger doses of $B_{1}$ parenterally.

\section{CONCLUSIONS}

1. The excretion of thiamine into the urine is directly related to the size of the dose of the vitamin.

2. The pattern of thiamine excretion in relation to the dose, as computed from observations on 6 normal subjects, was uniform and could be expressed by two linear equations.

3. Three patients with diabetes mellitus and one with hyperthyroidism deviated significantly from the normal pattern of thiamine excretion.

4. The urinary excretion of pyrimidine increases as the dose of thiamine is increased. Urinary pyrimidine plus urinary thiamine accounts for practically all of the thiamine administered.

5. After complete saturation of the tissues with thiamine, the body discharges excesses of the vita$\min$ at a rate which can be represented by a linear equation.

6. There is little justification for the injection of thiamine in doses of more than $35 \mathrm{mgm}$.

\section{BIBLIOGRAPHY}

1. Westenbrink, H. G. K., and Goudsmit, J., Relation between uptake and excretion of aneurin in humans. Nederl. tijdschr. v. geneesk., 1937, 81, 2632. Ibid., 1938, 82, 518. Arch. neerl. de physiol., 1937, 22, 319.

2. Jowett, $M$., Estimation of vitamin $B_{1}$ in urine. Biochem. J., 1940, 34, 1348.
3. Robinson, W. D., Melnick, D., and Field, H., Jr., Urinary excretion of thiamine in clinical cases and the value of such analyses in the diagnosis of thiamine deficiency. J. Clin. Invest., 1940, 19, 399.

4. Melnick, D., Field, H., Jr., and Robinson, W. D., A quantitative study of the urinary excretion of thiamine by normal individuals. J. Nutrition, 1939, 18, 593.

5. Borson, H. J., Clinical application of thiochrome reaction in study of thiamine (vitamin $B_{1}$ ) deficiency. Ann. Int. Med., 1940, 14, 1.

6. Melnick, D., and Field, H., Jr., Thiamine clearance as an index of nutritional status. J. Biol. Chem., 1941, 140, xc.

7. Light, R. F., Schultz, A. S., Atkin, L., and Cracas, L. J., The excretion of vitamin $B_{1}$ in the urine and feces. J. Nutrition, 1938, 16, 333.

8. Mason, H. L., and Williams, R. D., The urinary excretion of thiamine as an index of the nutritional level: assessment of the value of a test dose. $\mathrm{J}$. Clin. Invest., 1942, 21, 247.

9. Benson, R. A., Slobody, L. B., Witzenberger, C. M., and Lewis, L., Further studies on the urinary excretion of thiamin in children. J. Pediat., 1942, 20, 454 .

10. Ritsert, K., Uber die Ausscheidung von peroral und parenteral zugeführtem Aneurin. Klin. Wchnschr., 1938, 17, 1397.

11. Ishihara, I., Vitamin $B_{1}$ tolerance in man. J. A. M. A., 1941, 117, 1396.

12. Alexander, B., The chemical determination of thiamine and cocarboxylase in biological material. J. Biol. Chem., 1943, 151, 455.

13. Ferrebee, J. W., Weissman, N., Parker, D., and Owen, P. S., Tissue thiamin concentration and urinary thiamin excretion. J. Clin. Invest., 1942, 21, 401.

14. Pollack, H., Ellenberg, M., and Dolger, H., Excretion of thiamine and its degradation products in man. Proc. Soc. Exper. Biol. and Med., 1941, 47, 414.

15. Wertz, A. W., and Mitchell, H. S., Thiamin and pyrimidine studies in older subjects. Proc. Soc. Exper. Biol. and Med., 1941, 48, 259.

16. Schultz, A. S., Atkin, L., and Frey, C. N., A method for the determination of thiamine and certain of its metabolic products in urine. J. Biol. Chem., . 1940, 136, 713.

17. Alexander, B., and Landwehr, G., Studies of thiamine metabolism in man. I. Thiamine balance. The normal requirement of vitamin $B_{1}$ and the rôle of fecal thiamine in human nutrition. J. Clin. Invest., $1946,25,287$.

18. Alexander, B., and Levi, J. E., A simple method for the chemical determination of urinary thiamine based upon the Prebluda-McCollum reaction. J. Biol. Chem., 1942, 146, 399.

19. Marrack, J., and Höllering, H. F., Excretion of injected aneurin. Lancet, 1939, 1, 325. 
20. von Drigalski, W., Zerstörung von parenteral zugeführtem Vitamin $B_{1}$. Zugleich ein Beitrag zur Frage einer Vitamin $B_{1}$ Belastung. Klin. Wchnschr., 1939, 18, 99.

21. Stähler, F., Untersuchungen über den Vitamin $B_{1}$ Stoff wechsel gesunder und polyneuritischkranker Schwangerer und Wöchnerinnen. Deutsche med. Wchnschr., . 1938, 64, 1137.

22. Lockhart, H. S., Kirkwood, S. B., and Harris, R. S., The effect of pregnancy and puerperium on the thiamine status of women. Am. J. Obst. and Gynec., 1943, 46, 358.

23. Rundles, $R$ W., Diabetic neuropathy. Medicine, 1945, 24, 111.

24. Cowgill, G. R., and Palmieri, M. L., Studies in the physiology of vitamins. XXII. The effect of experimentally induced hyperthyroidism on the vita- $\min B$ requirement of pigeons. Am. J. Physiol., 1933, 105, 146.

25. Williams, R. H., Egaña, E., Robinson, P., Asper, S. P., and Dutoit, C., Alterations in biologic oxidation in thyrotoxicosis. I. Thiamine metabolism. Arch. Int. Med., 1943, 72, 353.

26. Leong, $P$. C., Vitamin $B_{1}$ in the animal organism. II. Quantitative study of metabolism of vitamin $B_{1}$ in rats. Biochem. J., 1937, 31, 373.

27. Williams, R. H., and Bissell, G. W., Thiamine metabolism with particular reference to the role of the liver and kidneys. Arch. Int. Med., 1944, 73, 203.

28. Borsook, H., Buchman, E. R., Hatcher, J. B., Yost, D. M., and McMillan, E., The course of thiamin metabolism in man as indicated by the use of radio-active sulfur. Proc. Nat. Acad. Sc., 1940, 26, 412. 